\title{
A expansão dos colégios militares em Goiás e a diferenciação na rede estadual
}

\section{The expansion of military schools}

and the differentiation in the state system

\section{La expansión de los colegios militares \\ y la diferencia en la red estadual}

\author{
MÍRIAMFÁBIA ALVES* \\ Universidade Federal de Goiás, Goiânia- GO, Brasil. \\ MIRZA SEABRA TOSCHI ${ }^{* *}$ \\ Universidade Estadual de Goiás, Anápolis- GO, Brasil. \\ NEUSA SOUSA RÊGO FERREIRA \\ Secretaria Municipal de Educação, Aparecida de Goiânia- GO, Brasil.
}

\begin{abstract}
RESUMO: O ponto de partida é o movimento que possibilitou a entrega das escolas estaduais para a Polícia Militar, a expansão do número de colégios militares e as mudanças que aconteceram neste processo e como o governo de Goiás transformou uma ação isolada em política pública de diferenciação da rede estadual. Reuniu-se estudos, a legislação e as mensagens governamentais ao longo de 20 anos para atender as demandas da Polícia Militar que se transformaram em uma forma de diferenciação da rede estadual, selecionando o público atendido e transformando a educação em moeda de troca, a ameaçar o direito dos adolescentes e jovens à educação de qualidade.

Palavras-chave: Militarização. Escolas Estaduais. Goiás. Disciplina. Favores Políticos.
\end{abstract}

* Doutora em Educação pela Universidade Federal de Minas Gerais. É professora associada na Faculdade de Educação e docente no Programa de Pós-Graduação em Educação da Universidade Federal de Goiás. E-mail:<miriamfabia@gmail.com>.

** Doutora em Educação pela Universidade Metodista de Piracicaba. Pós doutora em Educação pela Universidade de Brasília. Docente de ensino superior e na pós stricto sensu da Universidade Estadual de Goiás. E-mail:<mirza.seabra@gmail.com>.

*** Graduada em Pedagogia pela Universidade Federal de Goiás, instituição onde atualmente é mestranda. É professora da Secretaria Municipal de Educação de Aparecida de Goiânia e professora da Secretaria Estadual de Educação. E-mail: <neusass2012@hotmail.com>. 


\begin{abstract}
The starting point is the movement that enabled the handover of state schools to the Military Police, the expansion of the number of military collisions and the changes that occurred in this process and how the government of the state of Goiás transformed an isolated action into distinctive public policy of the state school system. Studies, legislation, and 20 years of government messages were gathered to meet the demands of the Military Police that have transformed this into a form of differentiation in the state system, selecting the public assisted and transforming education in a currency of exchange, threatening the right of teenagers and young adults of quality education.
\end{abstract}

Keywords: Militarization. State Schools. Goiás. Discipline. Political Favors.

RESUMEN: El punto de partida es el movimiento que posibilitó la entrega de las escuelas estaduales para la Policía Militar, la expansión del número de colegios militares y los cambios que ocurrieron en este proceso y cómo el gobierno de Goiás transformó una acción aislada en política pública de diferenciación de la red estadual. Se reunieron estudios, la legislación y los mensajes gubernamentales a lo largo de 20 años para atender las demandas de la Policía Militar, que se transformaron en una forma de diferenciación de la red estadual, seleccionando el público atendido y transformando la educación en moneda de cambio que amenaza el derecho de los adolescentes y jóvenes a la educación de calidad.

Palabras clave: Militarización. Escuelas Estatales. Goiás. Disciplina. Favores Políticos.

\title{
Introdução
}

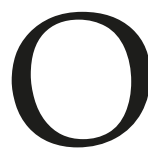

artigo pretende apresentar uma análise sobre o processo de militarização das escolas estaduais em Goiás. A crescente onda de transferência das escolas estaduais para a Polícia Militar no Brasil ${ }^{1}$ e, em especial, no Estado de Goiás, traz à tona a necessidade de discussão e análise desse modelo de política educacional e das implicações para o campo da educação pública como direito de todos, como também da gestão democrática das escolas públicas, do saber pedagógico e das finalidades da escola.

A quem interessa a militarização? Quem são seus maiores beneficiados? Por que militarizar algumas escolas e não investir numa política educacional para toda a rede 
estadual? Estas questões que nos mobilizam a compreender este fenômeno em Goiás tomam como ponto de partida o movimento histórico que possibilitou a entrega das escolas estaduais para a Polícia Militar, a expansão do número de escolas e as mudanças que aconteceram neste processo, além de buscar entender como o governo do estado foi expandindo esse subsistema dentro da rede pública estadual. A problemática principal que norteou a reflexão pode ser assim apresentada: como o governo de Goiás transformou uma ação isolada em política pública de diferenciação da rede estadual de Goiás? Para a discussão se reuniu estudos realizados sobre o tema, a legislação e as mensagens governamentais que solicitam a criação das escolas militares.

O artigo está organizado em duas partes: na primeira, analisamos o processo de criação dos Colégios da Policia Militar (CPMG); e, na segunda, a expansão dos CPMG e as mudanças que foram acontecendo em torno da criação dos novos colégios.

\section{Em nome da disciplina e da segurança pública}

Em 1999, Marconi Perillo² assumiu pela primeira vez o cargo de governador do estado de Goiás, com uma vitória inesperada contra Iris Rezende Machado (PMDB). A tônica de sua campanha era quebrar "as panelinhas" que dominavam o estado, ou melhor dizendo, a "familiocracia" comandada por Iris Rezende. Na esteira da política praticada por Iris Rezende, começava um longo período de domínio do governador, que se estende até o momento atual. (ZYLBERBERG et al., s.d.). Foi durante este período que os chamados colégios da Policia Militar de Goiás (CPMG) ganharam materialidade.

A origem dos CPMG é atribuída a uma legislação do período da Ditadura Militar, a Lei $n^{\circ}$ 8.125, de 18 de junho de 1976, sancionada pelo governador biônico Irapuan Costa Júnior ${ }^{3}$, que tratava da Organização Básica da Polícia Militar do Estado de Goiás. Nesta lei havia a previsão de criação de uma Diretoria de Ensino como um "órgão de direção setorial do Sistema de Ensino", que "incumbir-se-ia do planejamento, coordenação, fiscalização e controle das atividades de formação, aperfeiçoamento e especialização de oficiais e praças" (GOIÁS, 1976, Art.17). A lei previa que essa Diretoria trataria da formação dos quadros da PM, ou seja, oficiais e praças e, apesar de incluir no Art. 23 o "Colégio da Policia Militar (CPM)" como órgão de apoio, não há nenhuma referência de que esse colégio seria para atender outro público que não a própria PM.

De acordo com Souza (1999), a Diretoria de Ensino foi instalada em 1987 e realizou mudanças na formação dos quadros da Polícia Militar, alterando suas finalidades e denominação em 1998. Neste último ano, a PM solicitou autorização ao Conselho Estadual de Educação, para ofertar o ensino fundamental e médio no colégio que inicialmente funcionaria na Academia de Polícia Militar. Naquele mesmo ano, o Departamento de Ensino tornou-se Direção de Ensino, Instrução e Pesquisa. 
A narrativa sobre a origem dos colégios militares, disponível no portal $\mathrm{CEPMG}^{4}$, dá conta de que:

O Colégio da Polícia Militar do Estado de Goiás - CPMG foi criado pela Lei 8.125, de julho de 1976 que trata da Organização Básica da Polícia Militar do Estado de Goiás, mas somente depois de 23 anos foi ativado pela Portaria de $\mathbf{n}^{\circ}$ 604, de 19 de novembro de 1998, iniciando seu funcionamento com 440 alunos nas instalações da Academia de Polícia Militar com apenas 6 salas de aula, nominado Colégio Militar Coronel Cícero Bueno Brandão (CEPMG, s.d.).

Essa narrativa tem sido utilizada para explicar a origem dos colégios geridos pela PM em Goiás e as pesquisas (BELLE, 2011; SANTOS, 2016) vêm abordando o fato de eles terem sido criados no período militar e instalados no período democrático. No entanto, é preciso compreender que a Lei de 1976 não cria um colégio militar para atender civis. Ao contrário, ela tem um público alvo bem definido: os dependentes do corpo de oficiais pertencentes à Polícia Militar, desejo concretizado apenas em 1998.

Constatamos, também, que há uma distorção entre o previsto e o materializado, pois o embrião dos CPMG é o Colégio Militar Coronel Cícero Bueno Brandão, criado pela Portaria da PM nº64/1998, que previa, para o ano de 1999, a abertura de matrículas para o ensino fundamental ( $5^{\mathrm{a}}$ a $8^{\mathrm{a}}$ série) e médio prioritariamente para "I - dependentes legais de Policiais Militares; II - servidores e dependentes legais de funcionários públicos". Apesar de não ser aberto à comunidade, esse colégio já previa o atendimento da população civil. Além disso, já incorporava a prática de contar com os professores da rede pública estadual, uma vez que no Art. $6^{\circ}$ a portaria determinava que o "corpo docente do CPMG será composto de oficiais da ativa e da reserva da PMGO, desde que habilitados para este mister, e professores da rede pública estadual, colocados à disposição da Corporação" (GOIÁS, 1998 apud SOUZA, 1999, p. 217).

Note-se que a proposta era voltada a atender, prioritariamente, os dependentes da PM, sendo que o Colégio funcionaria nas dependências da Academia de Polícia. Mesmo contando com a cessão de professores da rede estadual, não havia a posse de uma escola estadual por parte da PM que a tornasse gestora da unidade escolar, ou seja, o modelo inicial era muito diferente do que se tornou prática ao longo dos anos: a entrega das escolas estaduais para a gestão da PM, como ocorreu em escala crescente. Para compreender esse processo, precisamos abrir novas trilhas para essa investigação e analisar os motivos da entrega dos colégios.

Quais são os motivos do governo de Goiás para entregar as escolas estaduais à Policia Militar, instituição que não tem como finalidade principal a educação?

Analisando as mensagens do governo do estado, utilizadas como justificativas para a criação dos colégios e propostas nos projetos de lei de criação, podemos dizer que as narrativas foram se alterando ao longo dos anos. Em relação ao primeiros colégios, que estavam em funcionamento desde 1999, a lei que legalizou a criação é de 2001 e versava 
"sobre a criação, instalação e transferência de unidades na Polícia Militar do Estado de Goiás e dá outras providências", ou seja, os primeiros colégios militares foram legalizados por meio de uma lei que tratava da organização da PM e não de educação. Assim, a lei determinava que dentre as unidades criadas no Art. $1^{\circ}$, inciso XVI, estão os "Colégios da Polícia Militar, sediados em Goiânia, Região Noroeste, HUGO e Unidade Sul; em Anápolis, em Rio Verde e Itumbiara" (GOIÁS, 2001b). O oficio-mensagem que solicitava a criação dos referidos colégios tem como foco a PM e a segurança pública: "tenho me preocupado sobremaneira com a Polícia Militar" e, por isso, propõe a "criação de diversas unidades da PM com o propósito de incrementar, substancialmente, a política de segurança pública, para melhor atender aos anseios do nosso povo" (GOIÁS, 2001a). Este oficio não faz nenhuma menção aos colégios militares. Importa destacar o aspecto financeiro dessa criação, pois, apesar de a mensagem dizer que "a criação dessas unidades policiais militares não onerarão o erário estadual [...] devendo ocorrer somente o remanejamento de efetivo para cobrir a área de atuação das novas unidades que se pretende criar" (GOIAS, 2001a), o projeto de lei autorizava o governo do estado, "mediante proposta do Comandante-Geral da Polícia Militar", a "alocar recursos, praticar atos e implementar atividades necessários à execução desta lei" (GOIÁS, 2001a). Nessa primeira criação, o governo do estado não apresenta nenhum argumento que justifique a criação dos colégios. Ao contrário, inseridos numa lei que define a estrutura da Polícia Militar, eles se misturam às unidades policiais criadas. Consultando o processo disponível na Assembleia Legislativa de Goiás é possível constatar que o deputado relator da matéria também não faz nenhuma menção aos colégios e que as emendas apresentadas dizem respeito às unidades da PM nos municípios goianos.

Essa narrativa sofre uma mudança com o oficio mensagem n. 83, de 2013, dirigido à Assembleia Legislativa de Goiás, que tratava da criação dos colégios nas cidades de Goianésia, Valparaíso de Goiás, Aparecida de Goiânia, Goiás, Jataí, Novo Gama, e a segunda unidade em Anápolis. (GOIÁS, 2013a). O Projeto de Lei falava de prioridade para a instalação e o funcionamento dos colégios criados pela lei de maio daquele ano. Essa mensagem informava que a criação teria "impacto orçamentário da medida, estimado pela Secretaria de Estado de Segurança Pública e Justiça, é de R \$452.000,00 (quatrocentos e cinquenta e dois mil reais)" e apresenta como justificativa para criação:

A instalação de colégios militares nas cidades do interior do Estado, do mesmo modo que na Capital, constitui medida de segurança preventiva da mais alta eficácia, tendo em vista que, a par da educação de boa qualidade ministrada, não se podem desconhecer os valores da disciplina e da ordem, cultivados no seio dessas unidades escolares, na formação da juventude, especialmente, nos tempos atuais, em que a ausência de limites nesse segmento social responde em grande parte, como se sabe por seu lamentável extravio para as hordas do crime, daí, que essa medida vem sendo reclamada pela própria população, por meio formais de participação, inclusive, mediante listas de assinaturas (GOIAS, 2013a). 
A mensagem traduz o senso comum que embasou a expansão dos colégios em Goiás e pautou a mídia e a propaganda governamental: 1) são escolas de qualidade, apesar de não explicitar que qualidade é essa, nem quais meios são utilizados para alcançá-la; 2) reforça que estas escolas ensinam valores de disciplina e ordem; 3) as escolas são apresentadas como medida de segurança preventiva contra a violência que impera na sociedade; 4) a juventude não tem limites e, por isso, o "seu extravio para as hordas do crime", o que determina a necessidade dos colégios da PM; 5) a população reclama essa escola, inclusive realizando abaixo-assinados que peticionam esse modelo de colégio. No entanto, esses argumentos nos fazem refletir em direção a uma política educacional que garanta o direito à educação de qualidade a todos os cidadãos goianos, pois se a realidade goiana apresenta tais desafios, por que não investir em políticas públicas para a educação estadual para todas as escolas da rede e em melhorias de suas condições de funcionamento? Por que não investir em uma política de segurança pública que efetivamente pudesse combater os problemas crescentes da violência no estado? Poderíamos dizer que a criação e expansão dos colégios aposta na possibilidade formativa de uma pequena parcela da população, com Indicador Sócio Econômico (INSE ${ }^{5}$ ) mais alto, que teria acesso a estas escolas e nelas poderia permanecer. Essa política é excludente e não se propõe a garantir o direito à educação para todos os goianos.

Em 2015 se dá uma nova expansão dos colégios militares, mas, desta vez, ela acontece em meio a uma reação do governo do estado frente à greve dos profissionais da educação e como reação aos enfrentamentos públicos promovidos por um grupo de professores da rede estadual. Nas palavras de Santos (2016, p.25):

\footnotetext{
Durante um evento solene de entrega de bolsas atleta no Centro Cultural Oscar Niemeyer, em Goiânia, promovido pelo governo de Goiás, o governador Marconi Perillo perdeu o controle ao ser vaiado por educadores da rede estadual durante seu discurso. Os servidores da educação, em greve há mais de trinta de dias, reuniram-se na entrada do Centro Cultural e, durante o discurso do governador, protestaram e vaiaram.
}

Neste ato o governador anunciou novos colégios militares como "castigo" aos "professores baderneiros", o que também promoveu uma mudança na narrativa. O oficio mensagem n. 57, de 2015, dirigido a Assembleia Legislativa de Goiás, que propõe a criação dos cinco novos colégios, é uma boa fonte para explicitar as contradições que cercam esse processo. No inicio do texto é possível constatar as mudanças na narrativa: o oficio de 2013 tratava de "criação, instalação e o funcionamento na Polícia Militar do Estado de Goiás das unidades que especifica" e, em 2015, dizia respeito à "transformação das unidades de ensino que especifica em Colégios Militares" (GOIÁS, 2015a). Em meio ao clima tenso existente entre o governo do estado e os professores, a mensagem do governador explica que "tenho por adequada a iniciativa da propositura, logicamente sem deixar, em momento algum, de reconhecer o trabalho incansável dos educadores da Secretaria da Educação, que também têm evidenciado o Estado na conquista de bons 
resultados no cenário educacional" (GOIÁS, 2015a, grifos nossos). Parece correto afirmar que até esse período, apesar da expansão de 2013, o governo ainda vinha mantendo uma narrativa dúbia sobre o lugar dessa escola na estrutura do estado. Em 2015, no entanto, resolve publicizar a sua opção de entregar as escolas estaduais à Polícia Militar para que não pudessem se opor ao governo do estado, fazer greve ou manifestação, submetendo os profissionais da educação ao rigor disciplinar característico da PM, onde a disciplina e a obediência são obrigatórias.

Outra mudança, em 2015, diz respeito à justificativa apresentada para a criação de novos colégios militares: "os bons resultados apresentados pelos colégios militares, que proporcionam rigoroso padrão de qualidade, primeiro lugar no Índice de Desenvolvimento da Educação Básica (Ideb) de Goiás e destaque no Enem" (GOIAS, 2015a). Tal narrativa atinge diretamente os professores da rede estadual, pois se volta às questões pedagógicas, aos bons resultados escolares. Subliminarmente, a mensagem expressa como o governo do estado compreende este processo: os professores da rede estadual não têm a competência para produzir bons resultados e, por isso, é necessário transferir as escolas para a Polícia Militar. Essa narrativa desvela também a forma como o governador representa a categoria e como a trata.

No âmbito das mudanças produzidas quanto ao lugar destes colégios na rede estadual, importa destacar que, em 2017, sofreram uma mudança de nomenclatura e de Colégio da Polícia Militar passaram a se chamar Colégio Estadual da Polícia Militar de Goiás, o que legitima sua condição de colégio pertencente a rede estadual, porém diferenciado na gestão e nas relações. Além disso, foi criada no organograma da Secretaria de Educação, Cultura e Esporte, a Superintendência de Coordenação dos Colégios Militares, atribuindo novo status a estes colégios (GOIAS, 2017), o que, em alguma medida, expressa uma nova lógica de organização da rede estadual de Goiás. Buscamos, também, compreender essas mudanças a partir da análise dos dados de expansão dos colégios.

\section{A expansão dos colégios militares: trocas políticas e diferenciação na rede estadual}

O surgimento dos colégios militares como instituições escolares equipadas e preparadas materialmente, pedagogicamente e profissionalmente para oferecer uma educação de qualidade, e com a criação de um subsistema privilegiado pelo aparato público, chama a atenção por cobrarem taxas mensais e exigirem uniformes/fardas caros. impossíveis de ser custeados por famílias mais pobres. Além disso, excluem os alunos (indisciplinados, com problemas de aprendizagem) que não se ajustam à estrutura da escola.

O que move essa política de expansão dos colégios militares? Se observarmos os dados é uma política exclusiva do governador Marconi Perillo, que implantou 46 unidades de colégios militares, criando, até abril de 2018, 45 mais 32 unidades. A expansão é vertiginosa como podemos observar no Quadro 1: 
Quadro 1: Colégios da Polícia Militar criados por lei (2001-2018)

\begin{tabular}{|c|c|c|c|c|c|c|c|}
\hline Ano & 2001 & 2013 & 2014 & 2015 & 2016 & 2017 & 2018 \\
\hline $\begin{array}{l}\text { Qtde } \\
\text { CPMG } \\
\text { criados }\end{array}$ & 6 & 18 & 3 & 14 & 3 & 25 & 9 \\
\hline $\begin{array}{l}\text { Novos } \\
\text { Municípios } \\
\text { atingidos }\end{array}$ & $\begin{array}{l}\text { Goiânia } \\
\text { Itumbiara } \\
\text { Rio Verde } \\
\text { Anápolis }\end{array}$ & $\begin{array}{l}\text { Inhumas } \\
\text { Formosa } \\
\text { Goianésia } \\
\text { Valparaiso } \\
\text { Aparecida } \\
\text { de Goiânia } \\
\text { Goiás } \\
\text { Jataí } \\
\text { Quirinópolis } \\
\text { Porangatu } \\
\text { Novo Gama } \\
\text { Águas } \\
\text { Lindas } \\
\text { Jussara } \\
\text { Mineiros } \\
\text { Luziânia } \\
\text { Senador } \\
\text { Canedo } \\
\text { São Miguel } \\
\text { Pontalina }\end{array}$ & $\begin{array}{l}\text { Catalão } \\
\text { Santa } \\
\text { Helena } \\
\text { Palmeiras }\end{array}$ & $\begin{array}{l}\text { Posse } \\
\text { Itaberaí } \\
\text { Jaraguá } \\
\text { Itauçu } \\
\text { Goiatuba } \\
\text { Ceres } \\
\text { São Luís } \\
\text { de Montes } \\
\text { Belos } \\
\text { Caldas } \\
\text { Novas }\end{array}$ & $\begin{array}{l}\text { Itapuranga } \\
\text { Vianópolis } \\
\text { Goianápolis }\end{array}$ & $\begin{array}{l}\text { Goianira } \\
\text { Alexânia } \\
\text { Cidade } \\
\text { Ocidental } \\
\text { Cristalina } \\
\text { Iporá } \\
\text { Padre } \\
\text { Bernardo } \\
\text { Pires do Rio } \\
\text { Rubiataba } \\
\text { Santo } \\
\text { Antônio do } \\
\text { Descoberto } \\
\text { Pirenópolis } \\
\text { Morrinhos } \\
\text { Ipameri } \\
\text { Guapó } \\
\text { Petrolina de } \\
\text { Goiás } \\
\text { Itapaci } \\
\text { Nerópolis } \\
\text { Trindade } \\
\text { Crixás } \\
\text { Hidrolândia } \\
\text { Anicuns } \\
\text { Bom Jesus }\end{array}$ & $\begin{array}{l}\text { Barro Alto } \\
\text { Sancrerlândia } \\
\text { Uruaçu } \\
\text { Bela Vista } \\
\text { Edéia }\end{array}$ \\
\hline
\end{tabular}

Fonte: Quadro elaborado pelas autoras de acordo com as leis de criação dos CPMG 
Ao iniciar esta análise, é importante ressaltar que o termo criação, largamente utilizado para falar da transferência das escolas para a PM deve ser compreendido com ressalva, uma vez que não se trata de uma nova escola a ser criada, construída e que foi entregue a PM. Ao contrário, o governo define uma escola estadual que está em funcionamento, em geral, com boa estrutura física e a transfere para a PM. Outro dado importante é que nem todos os colégios criados foram implementados. Consultando o quadro disponível no portal da CEPMG, em 01 de maio de 2018, constatamos que se anunciam 46 unidades implantadas em 35 municípios (CEPMG, s.d), ou seja, mais da metade dos colégios criados não foram instalados, mas estes contam na Lei de criação.

Quanto à análise do Quadro 1 podemos constatar: 1) a Lei que deveria legalizar a situação dos colégios Vasco dos Reis e Hugo de Carvalho Ramos, em funcionamento desde 1999, cria mais um colégio em Goiânia e prevê a criação, sem indicar qual seria a escola militarizada, de mais três colégios no interior do estado; 2) de 2001 a 2013 nenhum outro colégio foi criado; 3) em 2007, a Lei no 16.152 mantinha a mesma lista de 2001;4) o ano de 2013 marca o inicio do processo de expansão e o número dos colégios militarizados salta de 6 para 18, atingindo 17 novos municípios no interior do estado. Em 2017 nova expansão com 25 colégios criados e 21 municípios atingidos.

Outro dado importante quanto à criação dos CPMG diz respeito à prerrogativa do Poder Executivo, o governo do estado, de tomar esta decisão, uma vez que compete ao ele a proposição de lei que implica impactos financeiros. No entanto, há movimento dos deputados goianos que começam a peticionar a transferência de outras escolas para a PM, bem como aprovar projetos de lei apresentados pelo Executivo goiano ${ }^{6}$. Na legislação consultada, apenas a criação dos CPMG de Catalão e Santa Helena de Goiás figuram como acréscimo da Assembleia Legislativa (GOIÁS, 2014). As leis de criação também foram sofrendo alterações ao longo dos anos: inicialmente, com exceção dos colégios de Goiânia, em 2001, a Lei indicava apenas a criação do colégio no município. A partir de 2013, o movimento se altera e alguns colégios passam a ser nominados na Lei de criação, ou mesmo, a que cria novas unidades nomeia os colégios criados por leis anteriores ${ }^{7}$. Neste aspecto, o prazo de implantação dos colégios ganha uma dinâmica diferente com a lei $n^{\circ} 18.967$ de 2015, que inaugurou um novo procedimento quanto aos prazos ao definir que: "É fixado o prazo de até 30 (trinta) dias para que a Secretaria de Educação, Cultura e Esporte e o Comando-Geral da Polícia Militar adotem todas as medidas administrativas necessárias para que as unidades de ensino ora transformadas em Colégios Militares passem a funcionar como tais em sua plenitude" (GOIÁS, 2015b). Mesmo que, em 2013, a Lei $\mathrm{n}^{\circ} 18.108$ fale em prioridade de instalação do colégio de Formosa (GOIÁS, 2013a), a de 2015 é diretiva quanto aos 30 dias que, em parte, corresponderam ao período de férias escolares na rede estadual, uma vez que o oficio foi enviado para a Assembleia Legislativa em 22 de junho. Deste modo, é notório que a implantação se deu autoritariamente e sem a participação da comunidade, e que nem mesmo as oposições a essa decisão, como 
aconteceu explicitamente no Colégio Waldemar Mundin, em Goiânia, cuja manifestação contrária à transformação da escola em colégio militar repercutiu no cenário goiano, não alterando a definição do governo do estado que teve o CPMG. De acordo com Santos (2016, p.38):

O processo de transferência das escolas públicas para a PM gerou resistência espontânea de parte da sociedade, a parcela atingida, que reagiu com protestos, debates e manifestações. Apesar das ações movidas por esses grupos, houve pouca divulgação nas mídias oficiais. No entanto, não deixou de haver divulgação: coube aos jornais alternativos e às redes sociais propagar os eventos de resistência.

Outro dado importante em relação à expansão dos colégios militares diz respeito ao período em que foi criado o maior número de colégios. Analisando a documentação disponível, as maiores expansões coincidem com o final de um mandato do governo, ou seja, 2013 e 2017, atingindo 22,76\% dos municípios goianos. Mas o que justificaria o número intenso de novos colégios e municípios atingidos em 2013 e $2017^{8}$ ? O ano de 2013 antecede ao pleito eleitoral de 2014 e o governador do estado, que tinha sido envolvido no ano de 2012 no escândalo do Carlinhos Cachoeira (ZYLBERBERG et. al., s.d.), estava com sua imagem abalada e concorreria às eleições de 2014. A criação dos colégios militares e a expansão para o interior acontecem neste momento, com a maior quantidade de colégios criados em apenas um ano, desde 2001. Nessa mesma perspectiva, o governo de Goiás aprovou novas leis de criação de CPMG em 2017, e o número de escolas salta novamente. Coincidentemente, a criação de novos colégios acontece em meio às expectativas para o pleito eleitoral de 2018, quando o governador se anuncia candidato ao Senado e pretende fazer como seu sucessor o seu vice no mandato 2015-2018.

Parece ser correto afirmar que, se os colégios militares passaram a ser objeto de desejo dos municípios goianos, o poder de criar um colégio e negociar com a comunidade local ganha novos contornos, que explicam a expansão desse modelo de escola em Goiás. Ao contrário da tão propagada melhoria da escola pública, se investe num novo modelo de gestão da escola, que marginaliza ainda mais a escola estadual com a criação do CPMG. O governo do estado não faz uma política pública que contemple melhorias para toda a rede, mas negocia algumas escolas que deixam de ser geridas na lógica de uma escola pública universal, gratuita, laica e para todos, criando uma diferenciação na rede. Ou seja, entrega as escolas para a Polícia Militar, o que contempla os anseios de uma parte da população atendida, e colhe os frutos de uma política excludente, autoritária e eleitoreira.

Uma outra perspectiva que explica esse desejo da população se relaciona ao discurso corrente de desvalorização da escola pública, o qual vem num crescente, desvirtuando o direito à educação pública. Os colégios geridos pela PM são colégios que se inserem na lógica de elitização de uma pequena parte das escolas estaduais para atender a um público que não teria condições de manter seus filhos em escolas privadas de alto custo, mas não se importam em pagar as contribuições impostas pela Associação de Pais e 
Mestres em troca de um escola que se propõe a oferecer disciplina e resultado. Nas palavras de Santos (2016, p.91):

A escola pública foi por muitos anos o espaço da elite e da exclusão das camadas mais pobres, segundo sua história de formação. Com a universalização do ensino, houve também a distinção entre aquele destinado à elite e o destinado à população geral, gerando conflito e embate. Nos últimos anos, as elites migraram para o ensino particular. Dessa maneira, os CPMG se tornaram uma nova forma de elitização do espaço público. Sua implementação tem finalidades específicas: instituir um tipo de escola que se distingue das outras escolas públicas; agrupar indivíduos dependentes dos PM, selecionando e excluindo parte dos alunos civis; criar parâmetros de controle das atividades e dos comportamentos da comunidade escolar; formar sujeitos pautados na naturalização da hierarquia e da disciplina, com a mesma estrutura das instituições militares.

No processo de elitização de uma parte das escolas estaduais que mexe com o imaginário da sociedade goiana, encontramos também os nexos para que o colégio possa tornar-se moeda de troca eleitoral, localizada, negociada e apresentada como solução das mazelas das escolas públicas e da sociedade. Uma propaganda enganosa e excludente.

Outro aspecto chama a atenção: por que a Polícia Militar vai deixando sua finalidade primeira, a segurança pública, para assumir a gestão das escolas? A expansão em curso representa uma grande movimentação de pessoal da PM para os colégios, o que, no mínimo, é paradoxal, com as críticas de falta de efetivo para cumprir sua função principal. Tentando compreender este movimento, buscamos identificar o pessoal envolvido com as escolas e os recursos dispendidos para essa finalidade. A lei $\mathrm{n}^{\circ} 18.357$ de 30 de dezembro de 2013 instituiu, no âmbito da Secretaria de Estado da Segurança Pública, as Funções Comissionadas de Administração Educacional Militar (FCEM) destinadas a uma jornada de oito horas diárias e com possibilidade de aumentar em 50\% o valor de cada FCEM em jornada de três turnos. Dentre os cargos remunerados estavam: diretor, vice-diretor, chefe administrativo-operacional e auxiliar administrativo-operacional, tendo sido criadas 264 FCEM, sendo 77 para três turnos, como podemos observar no quadro 2 (GOIAS, 2013c).

\section{Quadro 2: Funções Comissionadas para os Colégios da Polícia Militar em 2013}

\begin{tabular}{lcc|c|c}
\hline Denominação & $\begin{array}{c}\text { Valor por } \\
\text { 2 turnos }\end{array}$ & Quantitativo & & \\
\hline & & 2 turnos & 3 turnos & Total \\
\hline Diretor & $2.000,00$ & 0 & 11 & 11 \\
Vice-diretor & $1.600,00$ & 0 & 11 & 11 \\
\hline Chefe Administrativo-Operacional & $1.200,00$ & 33 & 33 & 66 \\
\hline Auxiliar Administrativo-Operacional & 800,00 & 154 & 22 & 176
\end{tabular}




\begin{tabular}{l|c|c|c|c}
\hline Denominação & $\begin{array}{c}\text { Valor por } \\
\text { 2 turnos }\end{array}$ & Quantitativo & & \\
\hline & & 2 turnos & 3 turnos & Total \\
\hline Total & & 187 & 77 & 264 \\
\hline
\end{tabular}

Fonte: Goiás, 2013c.

Esse quantitativo de FCEM vem crescendo significativamente, tendo saltado de 264 para 312 em 2014. Em 2016, o governo altera o quadro das FCEM com a criação de novos cargos que agora estão organizados da seguinte forma: Comandante, Subcomandante/ Chefe da D.E; chefe da divisão administrativa; auxiliar da divisão de ensino; auxiliar da divisão administrativa, guarda e auxiliar da divisão disciplinar (GOIÁS, 2016c). Assim, em 2016, o total de FCEM salta para 691 e o valor do cargo de diretor/comandante salta de $\mathrm{R} \$ 2.000,00$ para $\mathrm{R} \$ 3.500,00$ chegando a $\mathrm{R} \$ 5.250,00$ com o acréscimo de $50 \%$ pelo trabalho em três turnos. Considerando as últimas alterações na criação dos novos colégios, ainda sem contar com o impacto da Lei n 20.046 de 20.04.2018, o quadro da FCEM contabiliza 990 funções comissionadas, sendo 66 de Comandante ${ }^{9}$, o que indica o número de escolas que devem ser implantadas imediatamente, conforme demonstra o Quadro 3.

Quadro 3: Funções Comissionadas para os Colégios da Polícia Militar em 2018

\begin{tabular}{|l|c|c|c|c}
\hline Denominação & $\begin{array}{c}\text { Valor por } \\
\text { 2 turnos }\end{array}$ & Quantitativo & & \\
\hline & & 2 turnos & 3 turnos & Total \\
\hline Comandante & $3.500,00$ & 30 & 26 & $66^{*}$ \\
\hline Subcomandante/Chefe da D.E. & $3.000,00$ & 30 & 26 & 66 \\
\hline Chefe da Divisão Administrativa & $2.100,00$ & 30 & 26 & 66 \\
\hline Chefe da Divisão Disciplinar & & 30 & 26 & 66 \\
\hline Auxiliar da Divisão de Ensino & $1.400,00$ & 30 & 26 & 66 \\
\hline Auxiliar da Divisão Administrativa & & 30 & 26 & 66 \\
\hline Guarda & & 64 & 78 & 172 \\
\hline Auxiliar da Divisão Disciplinar & & 107 & 243 & 440 \\
\hline Total & & 351 & 477 & $990^{* *}$ \\
\hline
\end{tabular}

Fonte: Goiás, 2013c; 2018c

* O número foi mantido como consta como Anexo Único da Lei n 18.357, de 30 de dezembro de 2013, disponível no site do Gabinete Civil.

** O total foi reproduzido como consta como Anexo Único da Lei n 18.357, de 30 de dezembro de 2013, disponível no site do Gabinete Civil.

Esses dados nos fazem refletir com Cunha $(2007$, p. 810$)$ de que o processo de militarização das escolas estaduais em Goiás "é um processo cheio de meandros, que não 
comporta resposta simples", pois, para um estado que propagandeia ser moderno e enxuto, ao transferir a gestão das escolas para a PM cria uma máquina de produzir função gratificada que custa milhões aos cofres públicos. Esse dado fica ainda mais contraditório se os contrapormos à condição do magistério e suas possibilidades de receber função gratificada, pois, de acordo com a Lei, o professor só pode receber gratificação nos cargos de gestão se ocupar o cargo de diretor escolar e o valor é estabelecido conforme o número de alunos matriculados na escola. No entanto, uma escola com menos de 150 alunos não concede direito ao diretor de receber a gratificação, e o que se paga em função gratificada nas escolas estaduais, as quais tem remuneração para o diretor condicionada ao porte das escolas, que, para dois turnos, varia de $\mathrm{R} \$ 1.625,00$ a $\mathrm{R} \$$ 975,49. (GOIÁS, 2014d). Isso nos diz muito de como o governo pensa o atendimento escolar da população goiana e como lida com a rede estadual de educação em sua totalidade, uma vez que a mesma rede pública lida diversamente com questões que compõem o cotidiano escolar: a cobrança de taxas, a seleção e a possibilidade de exclusão dos alunos, a infraestrutura das escolas e as gratificações pagas aos profissionais que fazem a gestão da escola. Estas são questões para novas reflexões e investigações.

\section{Considerações finais}

Muito há para se falar e analisar sobre as escolas da Polícia Militar no estado de Goiás. Diferentes abordagens podem ser feitas sobre sua forma de organização, proposta pedagógica, dinâmica das aulas e do rigor disciplinar, o que pensam seus alunos, professores e funcionários. Podemos, ainda, propor análises sobre o perfil dos estudantes, dos professores, das famílias, do currículo, das relações entre os estudantes e desses com seus professores e militares que atuam na escola.

Nesse texto, a opção foi por refletir sobre o histórico de criação destes colégios no estado de Goiás e sua expansão e o processo de diferenciação que se tem produzindo na rede estadual de Goiás, ao longo dos últimos 20 anos. Se, inicialmente, os colégios criados para atender as demandas da Polícia Militar, ao longo dos últimos 20 anos, foram se transformando e provocando diferenciação da rede estadual de Goiás, uma vez que o número de colégios geridos pela PM vem crescendo, significativamente, desde 2013, como demonstram os dados apresentados.

Esse crescimento, percebido justamente nos anos que antecedem ao pleito eleitoral estadual, também nos provoca a refletir sobre a intencionalidade eleitoral do governo estadual em transferir um número tão grande de escola para a PM, bem como sua expansão para o interior do estado, o que, em alguma medida, também revela a aceitação por parte da sociedade deste modelo de escola. A narrativa construída acerca dos colégios militares nos últimos 20 anos, por diferentes interlocutores hegemônicos (governo do 
estado, mídia, Polícia Militar) enfatiza o sucesso dessas escolas em dois quesitos centrais: impor a disciplina e o bom rendimento dos alunos nas provas e exames nacionais. Essa narrativa tem ganhado a adesão da população e os colégios passaram a ser objeto de desejo de muitas famílias, as quais desejam uma escola de qualidade e segura para os seus filhos. No entanto, seria necessário questionar que escola e que formação as famílias desejam para os seus filhos? Qual a qualidade almejam em uma escola pública? Que impactos tem uma formação com doutrina militar vida dos adolescentes e jovens?

Ademais, a opção do governo estadual em transferir escolas estaduais para a Polícia Militar e em fazer disso uma política educacional nos leva a questionar a forma como se compreende a escola pública em Goiás, pois se o colégio militar é destacado como escola de qualidade e que impõe disciplina, o que dizer das escolas estaduais públicas de Goiás que não foram militarizadas? Seria justo comparar as condições de funcionamento das escolas estaduais e dos colégios militares? Nesse aspecto convém destacar que as efetivas condiç̧ões de funcionamento dos colégios militares são muito distintas das escolas estaduais: possuem excelente infraestrutura física, que mantém com as taxas que recebem dos familiares; contam com um substantivo reforço de pessoal, com altas funções gratificadas, para administrar e cuidar da disciplina; têm poder de administrar a permanência ou não dos alunos. Enquanto isso, as escolas estaduais convivem com a precariedade da infraestrutura, a falta de pessoal. Assim, a um pequeno grupo, o dos colégios militares, é garantida uma educação pública diferenciada, enquanto a maioria da população convive com a precariedade da escola e o abandono do poder público. Nesse processo, a desvalorização da escola pública vai acontecendo paulatinamente e a ela vai sendo atribuído um lugar social marginalizado na sociedade goiana.

Por fim, a militarização representa grave ameaça para a escola pública goiana, pois promove uma perversa diferenciação na rede estadual que ameaça o direito de todos à uma educação de qualidade. Na contramão do movimento que valoriza a disciplina e a militarização, reafirmamos que a garantia do direito à educação, num país de brutais desigualdades como o Brasil, só pode ser plenamente cumprido se o estado brasileiro cumprir com sua função constitucional e assumir a escola pública como espaço público e destinado a todos. Portanto, a militarização nega o direito e retoma a lógica da exclusão e da educação dual, tão características de nossa história.

Recebido em: 20/06/2018 e Aprovado em: 28/07/2018 


\section{Notas}

1 Em levantamento feito pela Folha de São de Paulo em 10/08/2015, o Brasil possuía 93 escolas da PM, sendo que a maior quantidade de colégios pertenciam aos estados de Goiás, Minas Gerais e Bahia. (BERTONI, 2015)

2 Marconi Perillo é filiado ao Partido da Social Democracia Brasileira (PSDB) e exerceu o cargo de governador do estado de Goiás nos seguintes mandatos: 1999 a 2002; 2003 a 2006; 2011 a 2014; e atualmente encontra-se em seu quarto mandato.

3 O termo "biônico" refere-se, na política, àquele cujo mandato político tenha ocorrido sem ter sido eleito ou participado de um pleito eleitoral, ou seja, às custas da indicação de um superior. Esse termo popularizou-se durante o período da ditadura (1964-1984), quando muitos chefes políticos e governantes se beneficiaram da indicação dos militares.

4 https://www.portalcepmg.com.br/

5 O INSE define um estrato dos alunos de cada escola e é definido pela posse de bens domésticos, renda, escolaridade dos pais e contratação de serviços pela família. É construído a partir de respostas dos alunos na Prova Brasil, Aneb e Enem.

6 O Governo do Estado de Goiás vem contando com maioria na Assembleia Legislativa, o que explica a facilidade em se aprovar os projetos de lei de criação de novos colégios militares. Seria importante mapear as narrativas dos deputados e os pedidos que surgem da Assembleia para a criação de outros colégios, o que não foi objeto de investigação neste artigo.

7 Por exemplo, em 2013, dos 19 colégios criados, 15 não foram nomeados, a Lei n 19.968/2018 nominou oito colégios criados em 2013 e sete criados em 2017. Isso implica uma nova ordem no processo de implantação dos CPMG (GOIÁS, 2013b; 2017; 2018).

8 A expansão ocorrida no ano de 2015, quando o governo criou 15 novos CPMG, pode ser explicada como uma retaliação ao movimento grevista ocorrido no primeiro semestre deste ano.

9 O Quadro 3 foi reproduzido tal como consta como Anexo Único da Lei no 18.357, de 30 de dezembro de 2013, disponível no site do Gabinete Civil. O anexo conta com a atualização da Lei no 19973, de 15.01.2018, e o número de FCEM foi reproduzido como está no Anexo atualizado.

\section{Referências}

BELLE, H. B. M. Escola de Civismo e Cidadania: Ethos do Colégio Beta da Polícia Militar de Goiás. Tese (Doutorado) - Pontifícia Universidade Católica de Goiás, Programa de Pós-Graduação Stricto Sensu em Educação, Goiânia, 2011.

BERTONI, E. Cresce no Brasil o número de escolas básicas públicas geridas pela PM. In. Folha de São Paulo, 10 de agos./2015. Disponível em: https://www1.folha.uol.com.br/educacao/2015/08/1666631cresce-no-brasil-o-numero-de-escolas-basicas-publicas-geridas-pela-pm.shtml.

CRUZ, L.A.C.M. Militarização das escolas públicas em Goiás: disciplina ou medo? Dissertação (Mestrado). Pontifícia Universidade Católica de Goiás, Programa de Pós-Graduação Stricto Sensu em Educação, Goiânia, 2017.

CUNHA, L.A. O desenvolvimento meandroso da educação brasileira entre o estado e o mercado. In. Educ.Soc., Unicamp: Campinas, v. 28, n. 100, p.809-829, out. 2007. 
GOIÁS, Lei № 8.125 de 18 junho de 1976. Dispõe sobre a organização básica da Polícia Militar do Estado de Goiás e dá outras providências. Disponível em: http://www.gabinetecivil.goias.gov.br/ leis_ordinarias/1976/lei_8125.htm.

Ofício Mensagem N. 115/01 de 30 de novembro de 2001. Assembleia Legislativa do Estado de Goiás, Goiânia, 2001.

Lei N. 14.050, de 21 de dezembro de 2001. Dispõe sobre a criação, instalação e transferência de Unidades na Polícia Militar do Estado de Goiás e dá outras providências. Disponível em: http://www. gabinetecivil.goias.gov.br/leis_ordinarias/2001/lei_14050.htm.

Lei N. 18.108, de 25 de julho de 2013. Dispõe sobre a criação, instalação e o funcionamento na Polícia Militar do Estado de Goiás das unidades que especifica e dá outras providências. Disponível em http://www.gabinetecivil.goias.gov.br/leis_ordinarias/2013/lei_18108.htm.

Lei N. 18.324, de 30 de dezembro de 2013. Cria os Colégios da Polícia Militar que menciona e dá outra providências. Disponível em http://www.gabinetecivil.goias.gov.br/leis_ordinarias/2013/ lei_18324.htm.

Lei N. 18.357, de 30 de dezembro de 2013. Institui, no âmbito da Secretaria de Estado da Segurança Pública, Funções Comissionadas de Administração Educacional Militar - FCEMs - para os fins e nos valores que menciona e dá outras providências. Disponível em: http://www.gabinetecivil. go.gov.br/pagina_leis.php?id=11215

Lei N. 18.556, de 25 de junho de 2014. Dispõe sobre a criação do Colégio da Polícia Militar de Goiás - CPMG que menciona e dá outras providências. Disponível em http://www.gabinetecivil.goias. gov.br/leis_ordinarias/2014/lei_18556.htm.

. Lei N. 18.967, de 22 de julho de 2015. Dispõe sobre a transformação das unidades de ensino que específica em Colégios Militares e dá outras providências. Disponível em: http://www.gabinetecivil. goias.gov.br/leis_ordinarias/2015/lei_18967.htm.

. Lei N. 19.066, de 21 de outubro de 2015. Introduz alterações na Lei no 18.967, de 22 de julho de 2015, que dispõe sobre a transformação das unidades de ensino que especifica em Colégios Militares e dá outras providencias. Disponível em http://www.gabinetecivil.goias.gov.br/leis_ordinarias/2015/ lei_19066.htm.

. Lei N. 19.437, de 30 de agosto 2016. Dispõe sobre modificações na Lei no 18.357, de 30 de dezembro de 2013, no seu Anexo Único, e dá outras providências Disponível em: http://www. gabinetecivil.goias.gov.br/leis_ordinarias/2016/lei_19437.htm

. Lei N. 19.779, de 18 de julho de 2017. Denomina Colégio Estadual da Polícia Militar de Goiás as unidades dos Colégios da Polícia Militar de Goiás e dá outras providências. Disponível em: http:// www.gabinetecivil.go.gov.br/pagina_leis.php?id=21657.

. Lei N. 19.880, de 01 de novembro de 2017. Altera a Lei n. 14.050, de 21 de dezembro de 2001, que dispõe sobre a criação, instalação e transferência de Unidades na Polícia Militar do Estado de Goiás e dá outras providências. Disponível em: http://www.gabinetecivil.go.gov.br/pagina_leis.php?id=22224

. Lei N. 19.651, de 12 de maio de 2017. Dispõe sobre a criação de Colégios da Polícia Militar do Estado de Goiás - CPMG - nos municípios que especifica, e dá outras providencias. Disponível em: http://www.gabinetecivil.go.gov.br/pagina_leis.php?id=21519

. Lei N.19.968, de 11 de janeiro de 2018. Altera a Lei n. 14.050, de 21 de dezembro de 2001, que dispõe sobre a criação, instalação e transferência de Unidades na Polícia Militar do Estado de Goiás e dá outras providências. Disponível em: http://www.gabinetecivil.go.gov.br/pagina_leis.php?id=22484 
Lei N. 19.973, de 15 de janeiro de 2018 . Dispões sobre a criação do Colégio Estadual da Polícia Militar de Goiás - CEPMG - que específica e dá outras providencias. Disponível em: http://www. gabinetecivil.go.gov.br/pagina_leis.php?id=22471

Lei N. 20.046, de 20 de abril de 2018. Dispõe sobre a denominação do Centro de Ensino em Período Integral - CEPI - que menciona e dá outras providências. Disponível em http://www. gabinetecivil.go.gov.br/pagina_leis.php?id=22583.

SANTOS, R.J.C. A Militarização da Escola Pública em Goiás. Dissertação (Mestrado). Pontifícia Universidade Católica de Goiás, Programa de Pós-Graduação Stricto Sensu em Educação, Goiânia, 2016.

SOUZA, Cibeli de. História da Politica Militar de Goiás. Goiânia, 1999.

ZYLBERBERG, S.; JALLES, C.; PAIVA, D.; MOTA, R.R.; PINHEIRO, L.. Marconi Ferreira Perillo Junior. FGV, http://www.fgv.br/cpdoc/acervo/dicionarios/verbete-biografico/marconi-ferreira-perillo-junior. 